\title{
บusisersaly
}

\section{Our friends across the water: Northern Ireland media coverage of the Scottish Independence Referendum}

Irwin, A. (2016). Our friends across the water: Northern Ireland media coverage of the Scottish Independence Referendum. In N. Blain, \& D. Hutchison (Eds.), Scotland's Referendum and the Media (pp. 132-144). Edinburgh University Press.

Link to publication record in Ulster University Research Portal

Published in:

Scotland's Referendum and the Media

Publication Status:

Published (in print/issue): 01/01/2016

\section{Document Version}

Publisher's PDF, also known as Version of record

\section{General rights}

Copyright for the publications made accessible via Ulster University's Research Portal is retained by the author(s) and / or other copyright owners and it is a condition of accessing these publications that users recognise and abide by the legal requirements associated with these rights.

\section{Take down policy}

The Research Portal is Ulster University's institutional repository that provides access to Ulster's research outputs. Every effort has been made to ensure that content in the Research Portal does not infringe any person's rights, or applicable UK laws. If you discover content in the Research Portal that you believe breaches copyright or violates any law, please contact pure-support@ulster.ac.uk. 


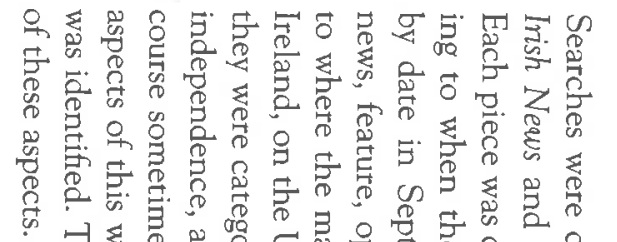

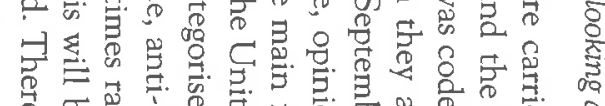

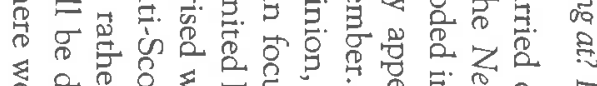

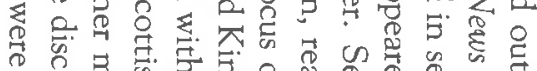

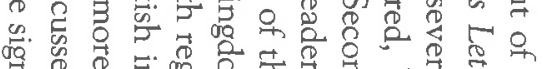

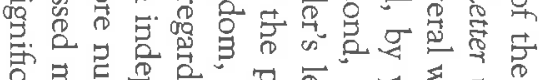

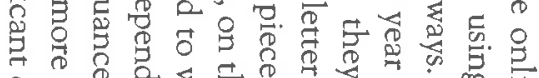

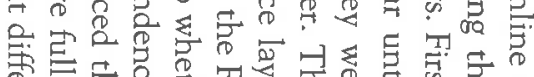

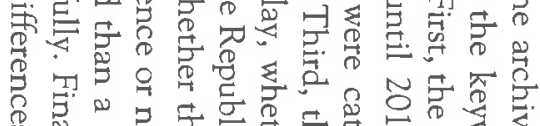

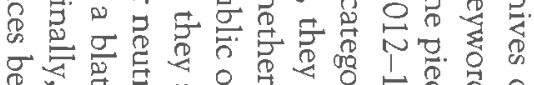

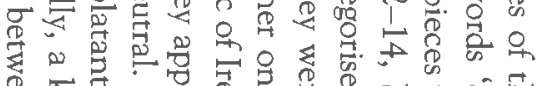

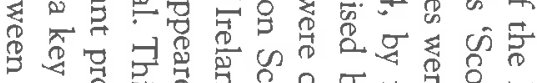

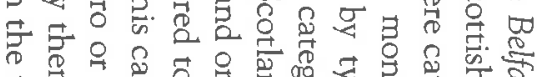

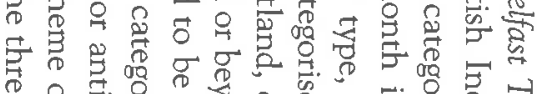

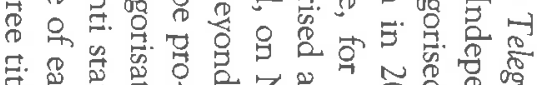

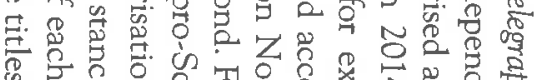

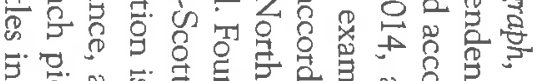

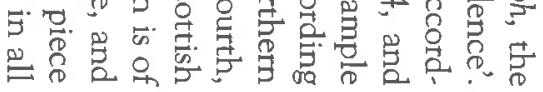

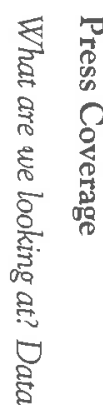

5
9
9
0
0
0
0

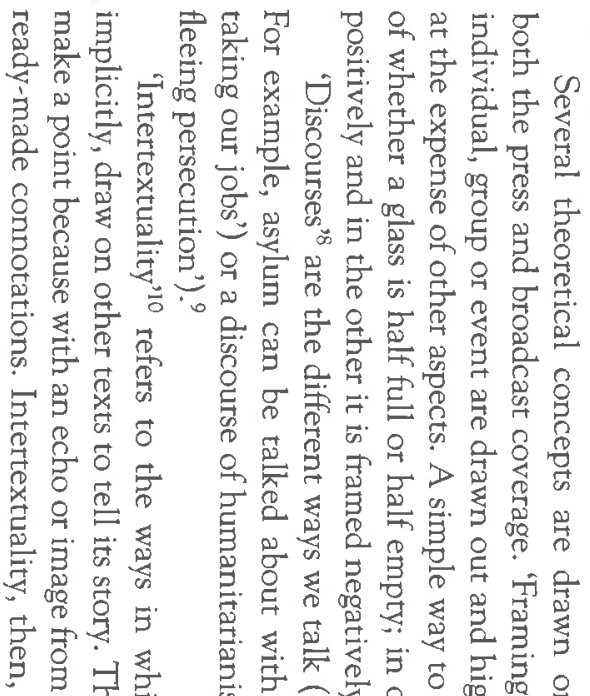
的害㤩官

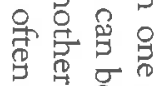

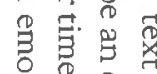

究.

के

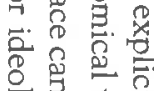

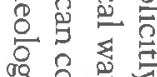

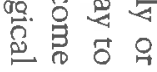

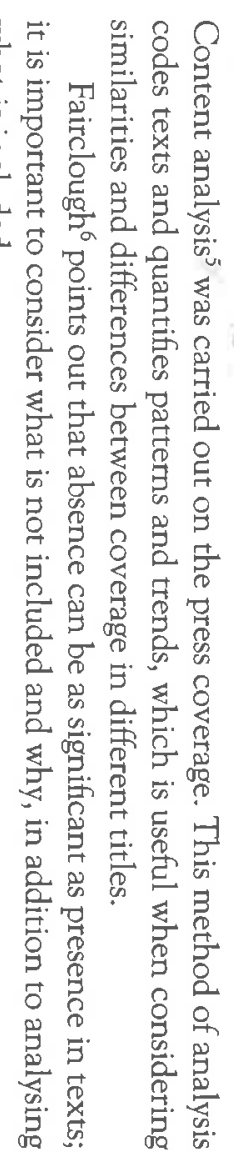

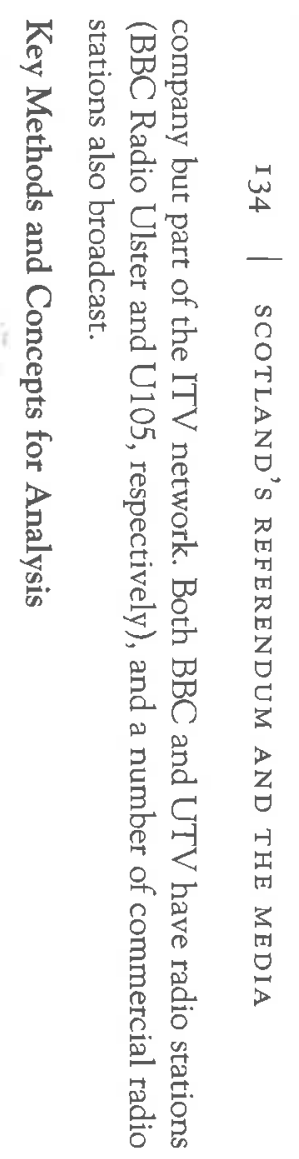

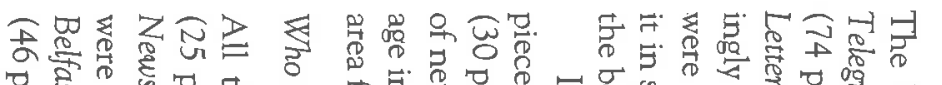

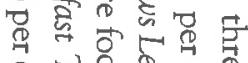

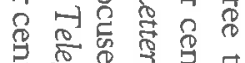

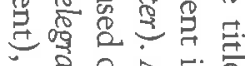
욕용

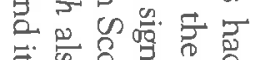

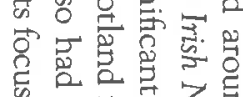

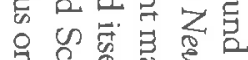

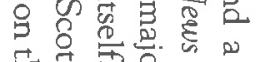

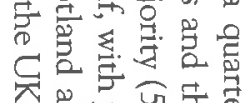

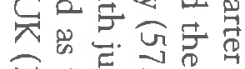

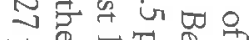

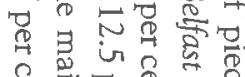

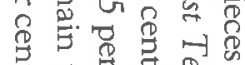

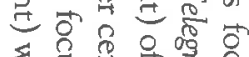

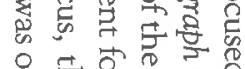

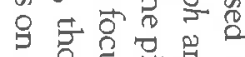

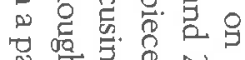

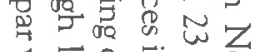

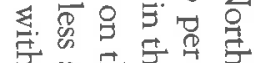

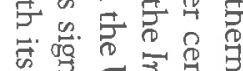

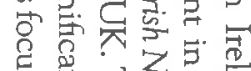

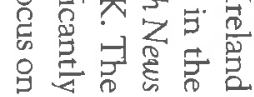

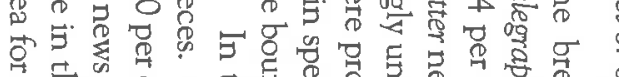
它. 居它.

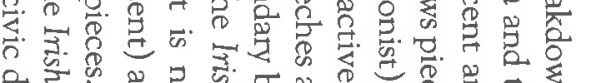

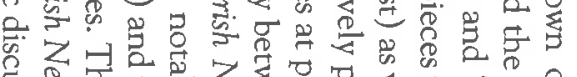

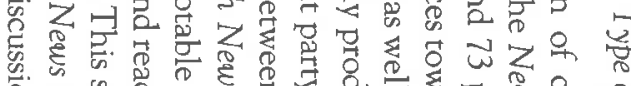
马े

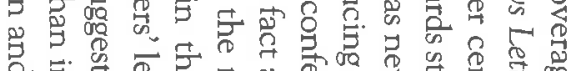

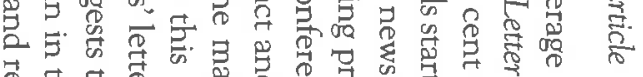

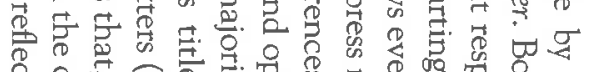

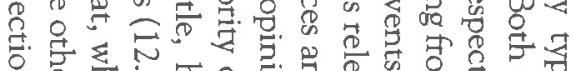

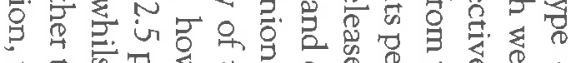

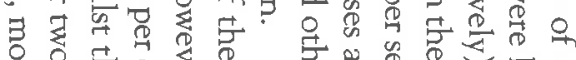

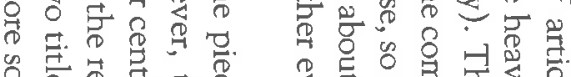

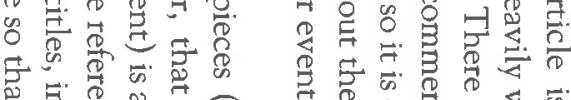

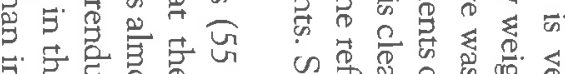

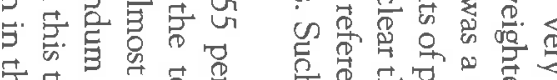

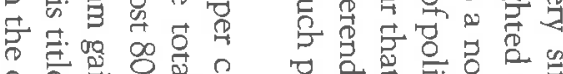

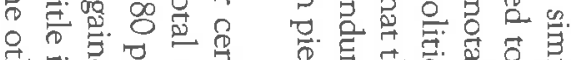

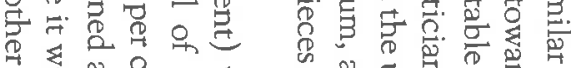

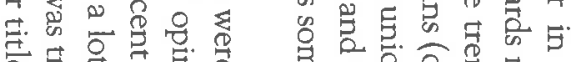
蛋

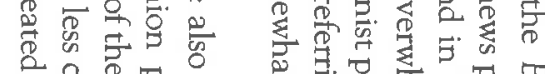
\& $0 \begin{aligned} & 0 \\ & 0\end{aligned}$

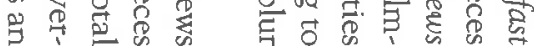

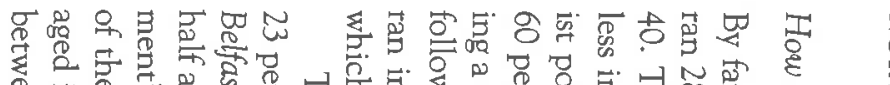

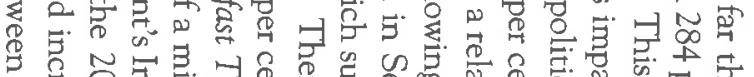

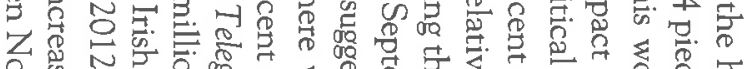

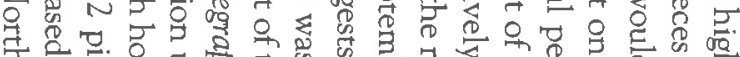

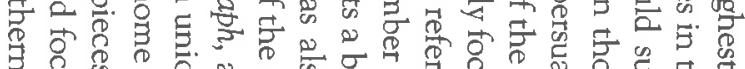

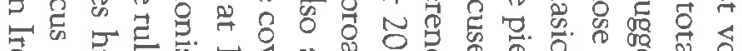

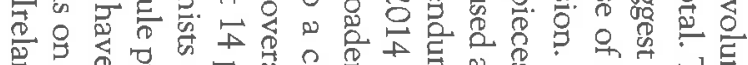

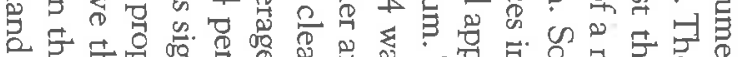

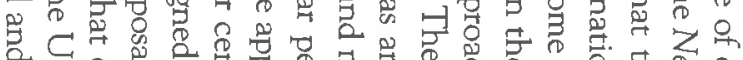

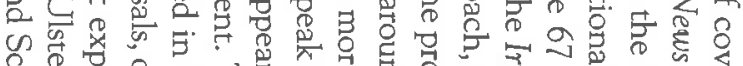

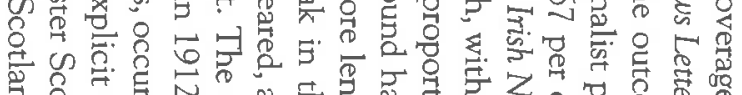

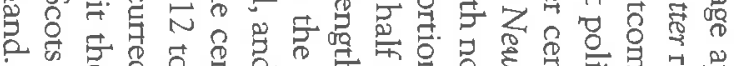

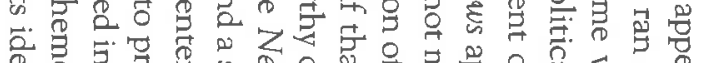

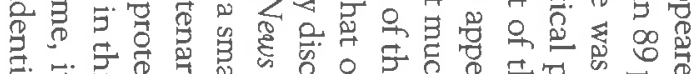

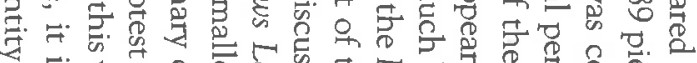

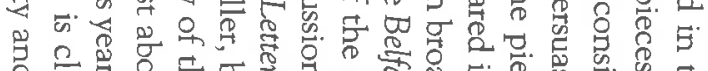

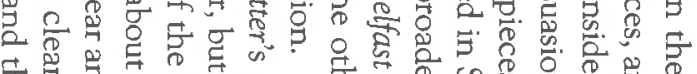

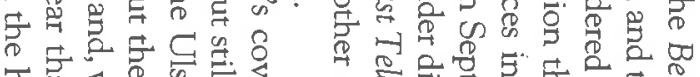

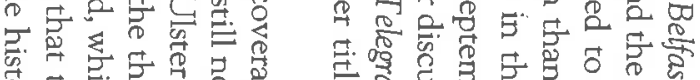

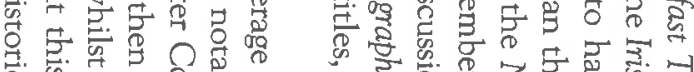

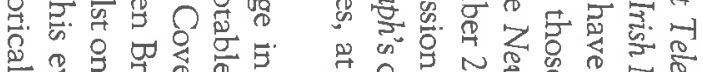

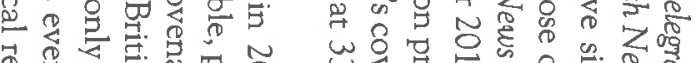

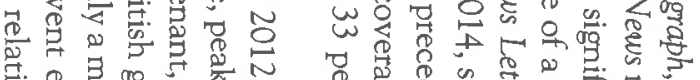

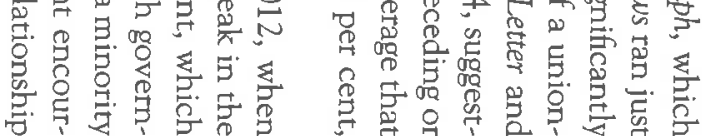



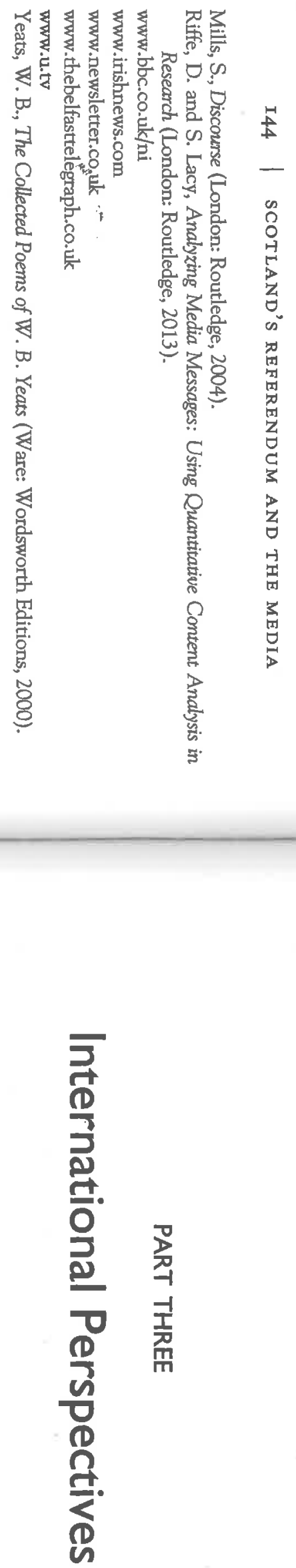